Provided for non-commercial research and education use. Not for reproduction, distribution or commercial use.

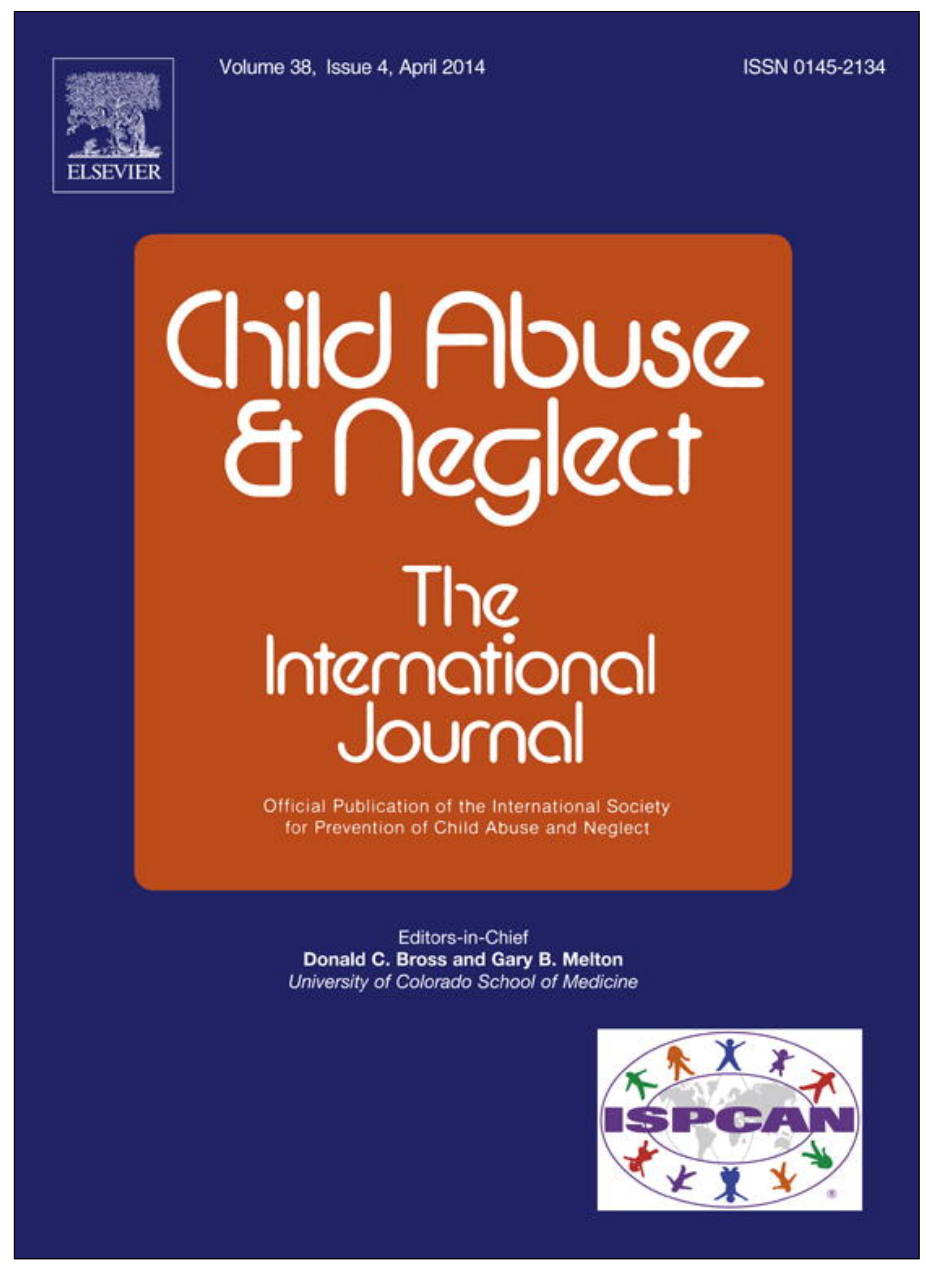

This article appeared in a journal published by Elsevier. The attached copy is furnished to the author for internal non-commercial research and education use, including for instruction at the authors institution and sharing with colleagues.

Other uses, including reproduction and distribution, or selling or licensing copies, or posting to personal, institutional or third party websites are prohibited.

In most cases authors are permitted to post their version of the article (e.g. in Word or Tex form) to their personal website or institutional repository. Authors requiring further information regarding Elsevier's archiving and manuscript policies are encouraged to visit:

http://www.elsevier.com/authorsrights 


\title{
Polyvictimization and its relationship to symptoms of psychopathology in a southern European sample of adolescent outpatients ${ }^{\text {is }}$
}

\author{
M. Soledad Álvarez-Lister ${ }^{\mathrm{a}, *}$, Noemí Pereda ${ }^{\mathrm{a}, \mathrm{b}}$, Judit Abad ${ }^{\mathrm{a}}$, \\ Georgina Guilera ${ }^{\mathrm{b}, \mathrm{c}}$, GReVIA ${ }^{1}$ \\ a Department of Personality, Assessment and Psychological Treatments, University of Barcelona, Passeig Vall d'Hebron, \\ 171, 08035 Barcelona, Spain \\ b Institut de Recerca en Cervell, Cognició i Conducta (IR3C), University of Barcelona, Barcelona, Spain \\ c Department of Methodology of the Behavioural Sciences, University of Barcelona, Passeig Vall d'Hebron, 171, 08035 Barcelona, Spain
}

\section{A R T I C L E I N F O}

\section{Article history:}

Received 2 July 2013

Received in revised form 5 September 2013

Accepted 7 September 2013

Available online 7 October 2013

\begin{abstract}
A B S T R A C T
This study examined the relationship between accumulated experiences of victimization and symptoms of psychopathology in 132 adolescent outpatients aged 12-17 years $(M=14.27 ; S D=1.42)$. The Juvenile Victimization Questionnaire and the Youth Self-Report were used to analyze polyvictimization and symptoms of psychopathology, respectively. The interviews were conducted between December 2009 and May 2012. Cluster analysis identified a subgroup of polyvictimized patients $(n=17)$ whose general psychological impairment was significantly worse and who presented significantly more externalizing and internalizing symptoms in comparison to the rest of the sample. This difference remained significant when taking into account the clinical severity of these symptoms. These results should be taken into account when assessing and treating adolescent outpatients, for whom an adequate prognosis must be made in line with their experiences and distress. Both the self-report technique and the statistical procedure used have been shown to be suitable for identifying victimization experiences in outpatients, although this new evidence requires confirmation in future research.
\end{abstract}

(c) 2013 Elsevier Ltd. All rights reserved.

\section{Introduction}

Research in child and adolescent victimology has mainly focused on the study of specific forms of victimization such as sexual abuse (e.g., Pereda, Guilera, Forns, \& Gomez-Benito, 2009; Whitaker et al., 2008), physical abuse (e.g., Jaffe, Caspi, Moffitt, \& Taylor 2004; Zolotor, Theodore, Runyan, Chang, \& Laskey, 2011), or bullying (e.g., Guerra, Williams, \& Sadek, 2011; Reijntjes, Kamphuis, Prinzie, \& Telch, 2010). However, it has become clear that these analyses only offer a partial view of the experience of child victims because children who have experienced one form of victimization are usually exposed to other forms (Finkelhor, Ormrod, Turner, \& Hamby, 2005; Higgins \& McCabe, 2000). This fragmented approach therefore makes it

\footnotetext{
is This work was supported by the Ministerio de Economía y Competitividad (MEC) [grant number DER2012-38559-C03-02], and the first author was supported by a PhD student fellowship from BECAS-CHILE, Comisión Nacional de Investigación Científica y Tecnológica (CONICYT).

* Corresponding author at: Departament de Personalitat, Avaluació i Tractament Psicològics, Facultat de Psicologia, Universitat de Barcelona, Passeig Vall d'Hebron, 171, 08035 Barcelona, Spain.

1 See Supplementary material for details of the members of GReVIA Working Group.
} 
impossible to assess the total impact of these cumulative experiences on child development, and the adverse consequences associated with each type of victimization have probably been overestimated (Turner, Finkelhor, \& Ormrod, 2006, 2010b).

The experience of different forms of victimization during childhood has been approached from a variety of perspectives. Some authors have conceptualized these experiences as multiple-type maltreatment (Higgins, 2004; Higgins \& McCabe, 2000). However, this notion only considers the cumulative action of different types of maltreatment (such as physical and sexual abuse, or neglect, among others). Other authors use the term complex trauma (Cook et al., 2005), which includes, in addition to maltreatment experiences, being exposed to other forms of interpersonal violence (e.g., sexual assault by a stranger, bullying, community violence) and other traumatic events in childhood (e.g., witnessing a natural disaster or an accident, having a chronic disease). Recently, and from a broader perspective, the accumulation during childhood and adolescence of interpersonal victimization experiences - defined as "harm that comes to individuals because of other human actors have behaved in ways that violate social norms" (Finkelhor, 2008, p. 23) - has been conceptualized as polyvictimization (Finkelhor, Ormrod, \& Turner, 2007, 2009). These authors have emphasized the high risk associated with the accumulation of such experiences, which have immediate and long-term adverse consequences for the child. Indeed, research has shown that polyvictimization exposes children and adolescents to particularly high levels of psychosocial risk (Finkelhor et al., 2007).

A number of recent studies have analyzed the epidemiology of polyvictimization and shown that community samples of North American children and youth report a high percentage of polyvictimization. Ford, Elhai, Connor, and Frueh (2010) evaluated 24 different types of victimization against children and adolescents aged between 12 and 17 years old, including different types of interpersonal victimization and being exposed to disaster/accidental trauma. Through latent class analysis, an empirical approach to assess polyvictimization, they found that $32.5 \%$ of the sample could be classified as polyvictims. Turner et al. (2010b) assessed lifetime interpersonal victimization in a sample of 4,053 children aged between 2 and 17 years. Polyvictims were categorized as respondents whose victimization levels fell in the top $10 \%$ of the sample (i.e., those who had experienced 11 or more different forms of victimization in their lifetime). Using the same methodology to assess polyvictimization, Cyr et al. (2013) evaluated 1,400 adolescents aged between 12 and 17 years in Canada. He found that polyvictims aged 12 to 14 years had experienced at least 7 victimizations, and 15 to 17 years had 9 or more victimizations. Radford, Corral, Bradley, and Fisher (2013) assessed a sample of 2,775 subjects in the UK aged between 11 and 17 years and found that polyvictims, defined as the $10 \%$ of children and youth with the highest victimization scores, presented 12 or more types of victimization throughout their lives.

\section{Polyvictimization and psychological distress in clinical populations}

The experience of polyvictimization has been associated with multiple and adverse consequences in children and adolescents (Chartier, Walker, \& Naimark, 2010; Cuevas, Finkelhor, Clifford, Ormrod, \& Turner, 2010; Cuevas, Finkelhor, Ormrod, \& Turner, 2009; Finkelhor, Hamby, Ormrod, \& Turner, 2005; Finkelhor, Ormrod, et al., 2005; Finkelhor et al., 2007; Ford et al., 2010; Higgins, 2004; Radford et al., 2013; Scott, Smith, \& Ellis, 2010; Turner et al., 2006, 2010b). Research has shown high rates of both internalizing syndromes (e.g., depression, anxiety disorders, suicidal risks, posttraumatic stress disorder) and externalizing syndromes (e.g., behavior problems, substance abuse). Furthermore, polyvictims have been found to present higher levels of symptomatology than do those children and youth who have experienced chronically any one form of severe victimization (Finkelhor et al., 2007; Turner et al., 2006) such as physical or sexual abuse (Turner et al., 2010b). This adverse and cumulative effect of polyvictimization has been demonstrated by research conducted through various kinds of methodology, regardless of the type of violence studied, the age of the sample, or the mental health consequences assessed (Leventhal, 2007).

Psychiatric severity has also been established as a risk factor for victimization in childhood and adolescence (Cuevas et al., 2009; Turner, Finkelhor, \& Ormrod, 2010a; Turner et al., 2010b; Turner, Vanderminder, Finkelhor, Hamby, \& Shattuck, 2011), and for revictimization in adulthood (Cuevas et al., 2010), thereby revealing the complex interplay between victimization and psychiatric symptoms. Indeed, the fact that victimization and psychiatric symptoms are both a consequence and a risk factor at the same time underlines the importance of studying these issues in more detail (Cuevas et al., 2009).

Compared to the results obtained from community samples, analyses of clinical samples of child and adolescent inpatients have reported higher rates of victimization (Fehon, Grilo, \& Lipschitz, 2001) and shown that the accumulation of multiple victimizing experiences has an impact on the severity of psychiatric symptomatology (Boxer \& Terranova, 2008; Fehon et al., 2001; Ford, Connor, \& Hawke, 2009). Research has generally found there to be a correlation between victimization and externalizing problems (Boxer \& Terranova, 2008; Ford et al., 2009; Ford, Wasser, \& Connor, 2011). However, although some studies have reported correlations between victimization and internalizing problems (Boxer \& Terranova, 2008), others have obtained inconclusive results (Ford et al., 2009).

Several studies have analyzed polyvictimization in samples of children and adolescents, but to a lesser extend in samples of outpatients, one exception being the recent study by Ford et al. (2011). These authors examined the medical records of 295 patients aged between 5 and 17 years in order to analyze the relationship between psychiatric severity and polyvictimization. Using cluster analysis procedures, polyvictimization was conceptualized as the accumulation of experiences of sexual abuse, physical abuse, parental impairment (i.e., psychiatric illness, alcohol or substance use disorders, criminal history), and out-of-home placements (including fostering, adoption, residential care, inpatient care, detention, or incarceration). They found more externalizing behavior problems at the clinical level and higher levels of severe impairment 
among psychiatric polyvictims, which confirms the adverse effect of these experiences on adolescent outpatients. However, their results showed no differences in terms of internalizing problems.

In light of the above research, it is clearly crucial to consider a wide range of victimizations so as to assess the impact of cumulative exposure to victimization experiences on the mental health of children and youth, not least because of the implications it may have for their treatment and prognosis (Boxer \& Terranova, 2008). Studies with adults have found that treatment should be adjusted to deal with the consequences of polyvictimization (Ford \& Kidd, 1998; Nemeroff et al., 2003). Therefore the overall victimization profile should be considered in designing individualized therapeutic interventions, and research is needed to guide these decisions.

Moreover, the definition of polyvictimization should be explored further using diverse methodologies, and considering an empirical definition (using latent class analysis or cluster analysis) to the more used a priori definitions (as a categorical o dimensional variable: Ford et al., 2011). Furthermore, as Ford et al. (2011) emphasized, it is necessary to move away from retrospective evaluations using archival data which tend to be conducted with clinical populations (Larson, 1997) toward a greater use of self-reports, especially if the aim is to clarify the possible relationship between polyvictimization and psychopathology, particularly internalizing symptomatology.

In this context, the present study adds new information regarding the epidemiology of victimization and polyvictimization in the international context. The small amount of research conducted in this area to date has mainly been carried out in North America and in northern European countries, and hence there is a need for further studies in countries with different cultural backgrounds to disentangle the influences of the various cultural dimensions that may underlie the differences observed.

\section{The present study}

The principal aim of this study was to evaluate, by means of self-reports, the relationship between polyvictimization and symptoms of psychopathology in a clinical sample of adolescent outpatients attending mental health services in a southern European country (Spain). A further objective was to empirically determine which percentage of adolescents make up the lifetime polyvictim group, given the substantial differences between the published studies (e.g., as a categorical variable depending on the age of the child in Finkelhor et al., 2009, and the top 10\% of the sample in Turner et al., 2010b; and as a dimensional variable with at least three victimizations in the ACE study by Anda et al., 2006).

The main hypotheses were: (a) there would be differences in the symptoms of psychopathology presented by the polyvictimized group and the rest of the sample, which comprised victims and non-victims; (b) polyvictims would also be more likely than the other adolescents to reach the clinical severity level $(T \geq 65)$ for internalizing and externalizing symptomatology and as regards their total YSR score; and (c) polyvictimization would be a strong predictor of the severity of internalizing and externalizing symptomatology and general distress.

\section{Method}

\section{Participants}

The sample comprised 132 adolescent outpatients ( $36.4 \%$ boys and 63.6\% girls) aged between 12 and 17 years ( $M=14.27$, $S D=1.42$ ) and who were interviewed in 14 child and adolescent mental health centers located in an eastern region of Spain. Interviews were conducted between December 2009 and May 2012. Most of the participants (81.1\%) were born in Spain, with the remainder coming from other European (3.2\%) or Latin American countries (14.4\%). In a small proportion (1.5\%) the origin was unknown. Application of an adapted version of the Hollingshead Index (1975) indicated that $9.8 \%$ of the sample could be classified as low socioeconomic status $(n=13), 31.8 \%$ as medium-low $(n=42), 22.7 \%$ as mid-level $(n=30), 19.7 \%$ as medium-high $(n=26)$, and $0.8 \%$ as high status $(n=1)$. The remaining participants $(15.2 \%, n=20)$ did not provide enough information to calculate this index.

A formal clinical diagnosis was only accessible for some cases, but based on the available information (i.e., reason for consulting or clinician impression), an approximate classification has been made using DSM-IV-TR criteria (American Psychiatric Association, 2000). The most frequent diagnoses or symptomatology related to them were: adjustment disorders (23.8\%), anxiety disorders (19.1\%), and attention-deficit and disruptive behavior disorders (16.4\%); and to a lesser extend mood disorders (7.0\%) and eating disorders (6.9\%). Also, $12.9 \%$ of participants consulted for other conditions not clearly related to any diagnoses (i.e., poor school achievement, relational problems).

\section{Measures}

Juvenile Victimization Questionnaire. A first version of the Juvenile Victimization Questionnaire (JVQ; Finkelhor, Hamby, et al., 2005), provided by its authors, was used. This instrument was then translated into Spanish and Catalan by the University of Barcelona's Research Group on Child and Adolescent Victimization (GReVIA). With the authors' permission, the item referring to statutory rape was not included in the translated versions as the concept does not feature in Spanish law and it is not meaningful in relation to the social standards and values regarding consensual sexual relationships in Spain. Two new items were added in relation to electronic victimization in order to evaluate harassment of children and adolescents via 
the Internet. The final draft therefore included 36 forms of victimization against children and youth, covering a wide range of victimizations and grouped into six modules: conventional crime (9 items), child maltreatment (4 items), victimization by peers and siblings ( 6 items), sexual victimization ( 6 items), witnessing and indirect victimization ( 9 items), and Internet victimization (2 items; Finkelhor, Hamby, et al., 2005; Finkelhor, Ormrod, et al., 2005; Hamby \& Finkelhor, 2001). The selfreport version of the JVQ may be applied to subjects between 8 and 17 years old (Hamby \& Finkelhor, 2001). Previous research has shown that the instrument has good reliability and validity (Finkelhor, Hamby, et al., 2005; Finkelhor, Ormrod, et al., 2005).

Youth Self Report/11-18. The Youth Self Report/11-18 (YSR, Achenbach \& Rescorla, 2001; translated by the Epidemiology and Diagnosis in Developmental Psychopathology Unit of the Autonomous University of Barcelona) is a self-report questionnaire for children and adolescents aged between 11 and 18 and it evaluates social competence (Part I) and emotional and behavioral problems (Part II). In the present study only the second part of the YSR was applied, including 119 items (rated on a Likert scale: $0-1$ and 2, from not true or infrequent, to very true or frequently true), of which 14 explore the frequency of adaptive or pro-social behaviors and the remainder evaluate a broad range of behavior problems. The YSR provides a number of measures: a score on the internalizing syndrome, referring to problems that cause psychological strain to the individual (e.g., anxiety, depression, withdrawal, somatization); a score on the externalizing syndrome, which refers to problems that cause discomfort in the subject's environment (e.g., delinquent and aggressive behavior); and a total problem score that constitutes a good indicator of the level of self-perceived distress and includes externalizing and internalizing scales, and also other problems such as attention or thought problems. The internal structure of the YSR has been confirmed in several countries with different cultural backgrounds (Ivanova et al., 2007), and its psychometric properties have already been tested with Spanish samples (Zubeidat, Fernández-Parra, Ortegal, Vallejo, \& Sierra, 2009). A T score $\geq 65$ on the YSR scales was established as the cut-off for clinical severity.

\section{Procedure}

Random sampling was used to select the child and adolescent mental health centers that would be invited to participate in the research. Approximately a third of these (31.6\%) declined to do so. Consent from parents/guardians and children/adolescents was only sought in cases which met the research criteria (i.e., individuals between 12 and 17 years old in the pre-diagnostic phase). Although a battery of psychological tests was used in the assessment interviews, only data related to demographic characteristics, symptoms of psychopathology, and victimization experiences will be presented in this paper. The study was previously approved by the Institutional Review Board of the University of Barcelona, as well as by an external Clinical Research Ethics Committee.

\section{Statistical analyses}

All statistical analyses were conducted using the program PAWS Statistics 18.0. To identify the polyvictims an empirical approach similar to that followed in other studies (Ford et al., 2009, 2010, 2011; Higgins, 2004) was used to define this group by means of cluster analysis. Because of the sample size, a lifetime victimization perspective was considered so as to favor the identification of a higher number of victimization experiences (Hamby \& Finkelhor, 2001). Specifically, a hierarchical cluster analysis was performed with the 36 variables of the JVQ that measure victimization (dichotomous items), the final solution being determined according to two criteria: (a) each cluster had to include at least $10 \%$ of the sample, in order to enable statistical comparisons between groups, and (b) clusters had to differ significantly $(p<.001)$ in relation to victimization modules, following the methodology used by Ford et al. (2011). Having identified the polyvictimization group and in order to test Hypothesis 1, bivariate analyses were used to compare the members of this group with the remaining participants in terms of demographic variables (sex, age, and country of origin), types of victimization (modules), internalizing and externalizing symptomatology, and YSR total problems scale (continuous variable standardized to $T$-scores). The socioeconomic status of participants was not considered because of the large number of missing values. For Hypotheses 2 and 3 a dichotomous measure was used to compare the severity of symptomatology ( $T$ score $\geq 65$ ) between the polyvictim group and the other adolescents. A logistic regression analysis was performed with these dichotomized measures of clinical severity, entering two blocks sequentially to test the effect of polyvictimization after controlling for demographic variables (the first block included sex, age, and country of origin, and the second added the polyvictimization variable).

Following Ford et al. (2011), dichotomized measures of severity were used for symptoms of psychopathology because clinical samples are skewed toward high scores and tend to violate the requirements of linear regression; this approach was also used because it was essential to clarify whether being a polyvictim was related to greater clinical severity in both internalizing and externalizing symptoms and in general psychological impairment.

\section{Results}

The hierarchical cluster analysis showed that the solutions with more than five clusters did not comply with the first selection criterion because of the small number of members in one or more clusters. Only solutions between three and five clusters had adequately sized groups ( $n \geq 10 \%$ ) and met the second criterion (all comparisons between modules had $p$ values 
$<.001$ ). Table 1 shows, for each cluster solution, the means of victimization for each module and the total number of lifetime victimizations. In all solutions, the third cluster always corresponded to the same group, and included high polyvictimized youths. This group represented $12.9 \%$ of the full sample $(n=17)$ and its members had a high average number of victimization experiences throughout their lifetime $(M=13.65, S D=2.34)$.

Because of our interest in comparing polyvictims with the remaining adolescent outpatients, we selected this third cluster and contrasted it with the rest of the participants in order to test our hypotheses.

Table 2 shows the demographic characteristics of the full sample, the polyvictim group, and the other cases, and also displays data regarding the presence of some form of victimization in each module and the average number of victimization types suffered by the adolescents throughout their lifetime. All but one case in the full sample had experienced at least one of the 36 forms of victimization. The polyvictim group as a whole had experienced at least one victimization in four of the six modules, whereas $35.3 \%(n=6)$ of the group had experienced at least one victimization in each module.

Bivariate analyses were performed to compare the polyvictim group with the rest of the sample, considering demographic variables, symptom variables, and type of victimization, as shown in Table 2. The polyvictim group did not differ from the remaining subjects in terms of sex, age, or country of origin. However, polyvictims were significantly different as regards the frequency of victimization related to conventional crime, child maltreatment, victimization by peers and siblings, sexual victimization, being a witness of victimization to others or indirect victimization, and victimization through the Internet. On average, the polyvictim group reported twice as many victimization experiences as did non-polyvictims for lifetime measure. Polyvictims also showed higher levels of impairment, both in terms of internalizing and externalizing problems and on the total problems scale.

Three binary logistic regression analyses were conducted (Table 3). A T score equal to or higher than 65 was used as the cut-off for severity, in order to compare the polyvictim group and the remaining adolescents as regards the clinical severity of symptomatology after controlling for sex, age and country of origin.

In each regression model the Hosmer-Lemeshow test did not show significant results, which is considered an indicator of good fit to the model. The left side of Table 3 shows the regression analysis for severe internalizing symptomatology in relation to demographic variables (Block 1) and polyvictimization (Block 2). Severe internalizing problems were not related to any of the demographic variables (Nagelkerke $R^{2}=.057$ ), but they were associated with polyvictimization (entered in Block 2), there being a statistically significant change in the variance explained (Nagelkerke $R^{2}=.146, R^{2}$ change $=.089$ ).

The central area of Table 3 shows the results of the second regression analysis, this time considering severe externalizing symptomatology and maintaining the two blocks entered previously. Demographic variables were not associated with clinically severe externalizing problems in Block 1 (Nagelkerke $R^{2}=.008$ ). However, in Block 2, polyvictimization was the only significant predictor of severity in externalizing problems, increasing significantly the variance explained by the model (Nagelkerke $R^{2}=.115, R^{2}$ change $=.107$ ).

Finally, the right side of Table 3 shows the regression analysis in relation to severity on the total problems scale, using the same procedure as before. No associations were found with the demographic variables entered in Block 1 (Nagelkerke $R^{2}=.001$ ), but when polyvictimization was entered in Block 2 it became the only significant predictor of severity on the total problems scale (Nagelkerke $R^{2}=.160, R^{2}$ change $=.159$ ).

For the three types of severity evaluated the odds ratios were significant and indicated that polyvictims were at least five times more likely to present a clinical level of psychopathological symptoms than were the other patients (OR $=4.977$ for internalizing symptomatology, $\mathrm{OR}=5.834$ for externalizing symptomatology, and $\mathrm{OR}=8.468$ for the total problems scale).

\section{Discussion}

The purpose of this study was to replicate cross-culturally the relationships between polyvictimization and the presence and severity of symptoms of psychopathology found in previous studies (Ford et al., 2011) in a clinical sample of adolescents from a southern European country (Spain). A comprehensive victimization measure was applied in order to assess a wide range of interpersonal victimizing experiences, data were gathered by means of self-report, and an empirical approach was used to assess polyvictimization by cluster analysis. As far as we are aware, this is the first study of its kind to be conducted in this cultural context.

The cluster analysis identified a subgroup of polyvictims, corresponding to around 1 in every 8 adolescent outpatients. Across their lifetime, adolescent polyvictims accumulated more episodes of victimization, and these episodes were related to a wide range of contexts (approximately five of the six evaluated modules). These figures are slightly higher than those reported by Ford et al. (2011) in North America, who found in their polyvictim group an average of four and a half victimizations out of the seven types of victimization evaluated in their clinical sample. At all events, both studies confirm that in clinical samples the experience of polyvictimization is not restricted to a particular context. On the contrary, these individuals end up being victimized in multiple contexts, with violence becoming, as Finkelhor puts it (2007), a vital and chronic condition for these children.

The present study has established empirically that the group identified as polyvictims represents about $13 \%$ of the sample, similar to the methodological criteria established by Finkelhor et al. (2009), who defined polyvictims as the top 10\% of the sample with the highest number of different victimization types experienced during lifetime. However, the number of victimization experiences defining polyvictims differs even among studies using the same criteria (Cyr et al., 2013; Radford 
Table 1

Comparison of means of three, four, and five cluster solution.

\begin{tabular}{|c|c|c|c|c|c|c|c|c|c|}
\hline \multicolumn{2}{|c|}{ Number of cluster } & \multirow[t]{2}{*}{$n(\%)$} & \multicolumn{7}{|l|}{$M$} \\
\hline & & & $\begin{array}{l}\text { Conventional } \\
\text { crime }\end{array}$ & $\begin{array}{l}\text { Child } \\
\text { maltreatment }\end{array}$ & $\begin{array}{l}\text { Victimization } \\
\text { by peer and } \\
\text { sibling }\end{array}$ & $\begin{array}{l}\text { Sexual } \\
\text { victimization }\end{array}$ & $\begin{array}{l}\text { Witnessing and } \\
\text { indirect } \\
\text { victimization }\end{array}$ & $\begin{array}{l}\text { Internet } \\
\text { victimization }\end{array}$ & $\begin{array}{l}\text { Lifetime } \\
\text { victimization }\end{array}$ \\
\hline \multirow[t]{2}{*}{ Three } & 2 & $66(55)$ & 2.70 & 0.95 & 1.11 & 0.27 & 1.62 & 0.29 & 6.94 \\
\hline & 3 & $17(12.9)$ & 4.47 & 2.24 & 2.12 & 1.06 & 2.94 & 0.82 & 13.65 \\
\hline \multirow[b]{3}{*}{ Four } & 1 & $49(37.1)$ & 0.98 & 0.06 & 0.53 & 0.06 & 0.98 & 0.12 & 2.73 \\
\hline & 2 & $47(35.6)$ & 2.66 & 0.98 & 1.19 & 0.34 & 1.83 & 0.30 & 7.30 \\
\hline & 3 & 17 (12.9) & 4.47 & 2.24 & 2.12 & 1.06 & 2.94 & 0.82 & 13.65 \\
\hline \multirow{5}{*}{ Five } & 1 & $49(37.1)$ & 0.98 & 0.06 & 0.53 & 0.06 & 0.98 & 0.12 & 2.73 \\
\hline & 2 & $31(23.5)$ & 2.13 & 1.13 & 0.81 & 0.48 & 1.68 & 0.42 & 6.65 \\
\hline & 3 & $17(12.9)$ & 4.47 & 2.24 & 2.12 & 1.06 & 2.94 & 0.82 & 13.65 \\
\hline & 4 & $16(12.1)$ & 3.69 & 0.69 & 1.94 & 0.06 & 2.13 & 0.06 & 8.56 \\
\hline & 5 & $19(14.4)$ & 2.79 & 0.89 & 0.89 & 0.11 & 1.11 & 0.26 & 6.05 \\
\hline
\end{tabular}


Table 2

Demographics, types of victimization, and clinical characteristics of the full sample and subgroups.

\begin{tabular}{|c|c|c|c|c|c|}
\hline \multirow[t]{2}{*}{ Dichotomous variables } & & \multicolumn{3}{|l|}{$n(\%)$} & \multirow[t]{2}{*}{ Statistic } \\
\hline & & Full sample $(n=132)$ & Polyvictims $(n=17)$ & Other cases $(n=115)$ & \\
\hline \multicolumn{5}{|l|}{ Gender } & \multirow[t]{3}{*}{$\chi^{2}(1)=1.389$} \\
\hline Male & & $48(36.4)$ & $4(23.5)$ & $44(38.3)$ & \\
\hline Female & & $84(63.6)$ & $13(76.5)$ & $71(61.7)$ & \\
\hline \multicolumn{5}{|l|}{ Origin } & \multirow[t]{3}{*}{$\chi^{2}(1)=0.268$} \\
\hline Spanish & & $107(81.1)$ & $13(76.5)$ & $94(81.7)$ & \\
\hline Foreign & & $25(18.9)$ & $4(23.5)$ & $21(18.3)$ & \\
\hline \multicolumn{6}{|l|}{ Victimization variables } \\
\hline \multirow[t]{2}{*}{ Conventional crime } & Yes & $109(82.6)$ & $17(100)$ & $92(80)$ & \multirow{2}{*}{$\chi^{2}(1)=4.117^{*}$} \\
\hline & No & $23(17.4)$ & $0(0)$ & $23(20)$ & \\
\hline \multirow[t]{2}{*}{ Caregiver maltreatment } & Yes & $66(50)$ & $16(94.1)$ & $50(43.5)$ & \multirow{2}{*}{$\chi^{2}(1)=15.192^{* * *}$} \\
\hline & No & $66(50)$ & $1(5.9)$ & $65(56.5)$ & \\
\hline \multirow[t]{2}{*}{ Peer and sibling victimization } & Yes & $84(63.6)$ & $15(88.2)$ & $69(60)$ & \multirow[t]{2}{*}{$\chi^{2}(1)=5.103^{*}$} \\
\hline & No & $48(36.4)$ & $2(11.8)$ & $46(40)$ & \\
\hline \multirow[t]{2}{*}{ Sexual victimization } & Yes & $23(17.4)$ & $10(58.8)$ & $13(11.3)$ & \multirow[t]{2}{*}{$\chi^{2}(1)=23.244^{* * *}$} \\
\hline & No & $109(82.6)$ & $7(41.2)$ & $102(88.7)$ & \\
\hline \multirow[t]{2}{*}{ Witnessing and indirect victimization } & Yes & $107(81.1)$ & $17(100)$ & $90(78.3)$ & \multirow[t]{2}{*}{$\chi^{2}(1)=4.559^{*}$} \\
\hline & No & $25(18.9)$ & $0(0)$ & $25(21.7)$ & \\
\hline \multirow[t]{2}{*}{ Internet victimization } & Yes & $98(74.2)$ & $12(70.6)$ & $22(19.1)$ & \multirow{2}{*}{$\chi^{2}(1)=20.508^{* * *}$} \\
\hline & No & $34(25.8)$ & $5(29.4)$ & $93(80.9)$ & \\
\hline \multirow[t]{2}{*}{ Continuous variables } & $M(S D)$ & & & & \multirow[t]{2}{*}{ Statistic } \\
\hline & Full sample & \multicolumn{2}{|c|}{ Polyvictims } & Other cases & \\
\hline Age & $14.27(1.42)$ & \multicolumn{2}{|c|}{$14.47(1.42)$} & $14.23(1.43)$ & $t(130)=0.636$ \\
\hline Lifetime victimizations & $6.24(4.04)$ & \multicolumn{2}{|c|}{$13.65(2.34)$} & $5.15(2.93)$ & \multirow{2}{*}{$\begin{array}{l}t(130)=11.431^{* * * *} \\
t(130)=3.679^{* * *}\end{array}$} \\
\hline YSR internalizing $T$ score & $58.45(8.46)$ & \multicolumn{2}{|c|}{$65.18(10.51)$} & $57.45(7.68)$ & \\
\hline YSR externalizing $T$ score & $58.33(9.67)$ & \multicolumn{2}{|c|}{$66.47(9.02)$} & $57.12(9.20)$ & \multirow{2}{*}{$\begin{array}{l}t(130)=3.919^{* * *} \\
t(130)=4.734^{* * *}\end{array}$} \\
\hline YSR total $T$ score & $59.45(8.00)$ & \multicolumn{2}{|c|}{$67.41(7.83)$} & $58.27(7.36)$ & \\
\hline
\end{tabular}

${ }^{*} p<.05$.

*** $p<.001$.

et al., 2013; Turner et al., 2010b). It would therefore be interesting to analyze further which of these methodologies is best able to identify those adolescents at greatest risk.

In line with previous research in both clinical (e.g., Boxer \& Terranova, 2008) and community samples (e.g., Turner et al., 2006) the present results confirm that the accumulation of victimization experiences increases the risk of psychological impairment in young people. Differences between polyvictims and the remaining patients were found for both internalizing and externalizing problems, as well as for general impairment, and this association was maintained even when the severity of clinical symptomatology was taken into account. These findings support our first and second hypothesis, and they are also consistent with reports from other countries (Boxer \& Terranova, 2008; Ford et al., 2009, 2011), which likewise provided evidence of the relationship between polyvictimization and severe externalizing symptomatology and general impairment. Furthermore, the present research also offers empirical support for the association between polyvictimization and severe internalizing symptomatology, thereby corroborating the results of Boxer and Terranova (2008) in their sample of inpatients.

Polyvictims were at least 5 times more likely than the rest of the sample to reach the established cut-off for clinical severity in our study, a fact which underlines the need to assess possible experiences of multiple victimizations in adolescent outpatients so that a prognosis can be made in accordance with their circumstances. Likewise, these results highlight the need, in clinical settings, to gather information about victimization experiences directly from young people themselves because, as previously reported (Ford et al., 2009, 2011), a significant number of adolescents who attend mental health services suffer from multiple victimization experiences during childhood and adolescence. Identifying polyvictimized children is also necessary in order to set appropriate therapeutic objectives and to increase the likelihood of a good response to treatment. This is especially important if one considers that symptoms may reappear or become more severe in adulthood (Chartier et al., 2010), a fact which suggests that therapy for these victims should be approached from a broader preventive perspective.

In relation to demographic variables there were no differences between polyvictims and the rest of the sample. Excluding the results of the country of origin, which are consistent with previous research (Ford et al., 2009, 2011), our results contrast with some other studies as regards sex and age. In clinical samples adolescent females tending to present greater levels of victimization (Ford et al., 2009, 2011). Although acknowledging that the male ratio is low in our sample, this discrepancy could also stem from differences in the cultural background of samples, but more research is needed to confirm this interpretation. Regarding age, Finkelhor et al. (2009) stated that the age of participants should be considered because the accumulation of victimization experiences or polyvictimization would be expected to increase over time. In the present study, average age did not differ between polyvictims and the rest of the sample, this being consistent with other results 
Table 3

Multivariate correlates of clinical severity of internalizing and externalizing symptomatology and clinically severe psychosocial impairment.

\begin{tabular}{|c|c|c|c|c|c|c|c|c|c|c|c|c|}
\hline & \multicolumn{4}{|c|}{ YSR severe internalizing $(T \geq 65)$} & \multicolumn{4}{|c|}{ YSR severe externalizing $(T \geq 65)$} & \multicolumn{4}{|c|}{ YSR severe total problems $(T \geq 65)$} \\
\hline & Wald $F$ & $p$ & OR & $95 \% \mathrm{Cl}$ & Wald $F$ & $p$ & OR & $95 \% \mathrm{CI}$ & Wald $F$ & $p$ & OR & $95 \% \mathrm{CI}$ \\
\hline Block 1 & \multicolumn{4}{|c|}{ Model $\chi^{2}(3)=5.194, p=.158$} & \multicolumn{4}{|c|}{ Model $\chi^{2}(3)=0.785, p=.853$} & \multicolumn{4}{|c|}{ Model $\chi^{2}(3)=0.086, p=.993$} \\
\hline Female gender & 2.622 & .105 & 1.106 & {$[0.855,5.164]$} & 0.583 & .445 & 0.742 & {$[0.345,1.595]$} & 0.079 & .778 & 1.129 & {$[0.486,2.622]$} \\
\hline Age & 0.509 & .475 & 2.102 & {$[0.838,1.461]$} & 0.031 & .861 & 0.977 & {$[0.750,1.272]$} & 0.010 & .919 & 0.985 & {$[0.743,1.307]$} \\
\hline Foreign origin & 1.403 & .236 & 0.564 & {$[0.219,1.455]$} & 0.095 & .758 & 1.165 & {$[0.442,3.071]$} & 0.003 & .953 & 1.031 & {$[0.370,2.870]$} \\
\hline Block 2 & \multicolumn{4}{|c|}{ Change $\chi^{2}(1)=5.576, p<.01$} & \multicolumn{4}{|c|}{ Change $\chi^{2}(1)=10.465, p<.001$} & \multicolumn{4}{|c|}{ Change $\chi^{2}(1)=14.919, p<.001$} \\
\hline Female gender & 1.973 & .160 & 1.951 & {$[0.768,4.958]$} & 1.254 & .263 & 0.631 & {$[0.282,1.412]$} & 0.015 & .903 & 0.945 & {$[0.383,2.334]$} \\
\hline Age & 0.347 & .556 & 1.092 & {$[0.815,1.462]$} & 0.119 & .730 & 0.952 & {$[0.722,1.256]$} & 0.103 & .748 & 0.951 & {$[0.699,1.293]$} \\
\hline Foreign origin & 1.303 & .254 & 0.566 & {$[0.213,1.504]$} & 0.219 & .640 & 1.280 & {$[0.455,3.600]$} & 0.060 & .807 & 1.149 & {$[0.377,3.506]$} \\
\hline Polyvictimization & 8.472 & .004 & 4.977 & {$[1.689,14.665]$} & 9.811 & .002 & 5.834 & {$[1.935,17.588]$} & 14.037 & .001 & 8.468 & {$[2.770,25.892]$} \\
\hline
\end{tabular}

Note. $\mathrm{OR}=$ odds ratio; $\mathrm{Cl}=$ confidence interval. In bold are highlighted the $\mathrm{OR}$ whose confidence interval did not includes the value of 1 . 
derived from clinical samples (Fehon et al., 2001; Ford et al., 2009), but it should be noted that considering age could be more important when covering a broad age period that includes both childhood and adolescence as in Finkelhor's studies.

\section{Limitations and possibilities for future research}

One of the main limitations of this study is the cross-sectional nature of the design, which makes it impossible to establish causal relationships between polyvictimization and clinical symptomatology. It should be noted, however, that there is clearly a complex interplay between victimization and symptomatology (Cuevas et al., 2009), which makes it rather hard to distinguish between risk and consequence. One reason for this is that high levels of externalizing and internalizing symptomatology may put children at greater risk for other types of victimization and revictimization, which would perpetuate the accumulation of these kinds of experiences (Turner et al., 2010a, 2010b, 2011).

The present study is also limited by the small sample size, although it should be acknowledged that clinical samples have special characteristics which make recruitment more difficult than is the case with community groups (Fehon et al., 2001). The unequal sex distribution may also have influenced the results obtained, especially in relation to the absence of differences between males and females, a finding that contrasts with some previous reports. Moreover, due to the fact that the interviews were conducted during the initial contact and assessment phase, no formal clinical diagnosis was available for the participants. Such a diagnosis would have been useful in terms of evaluating the possible contribution to psychiatric symptomatology, as reported by other studies (Ford et al., 2009, 2011).

An aspect that could limit the comparability with other studies is the exclusion of the item referred to as statutory rape in the victimization assessment tool. In Spain, the age of consent for sexual relation is low - 13 years of age - and the concept of statutory rape is not applied in this cultural context. As a result, the percentage of polyvictimizated adolescents could have been underestimated in comparison with studies from other countries that included this type of victimization (e.g., Turner et al., 2010b). A further limitation is that the present study did not control for the identity of aggressors, the frequency of victimization, or its severity. Consequently, it is not possible to determine the potential contribution of these variables, whether separately or jointly, to the risk of presenting symptoms of psychopathology. Nevertheless, and despite the fact that the study does not take these aspects into account, the results show that the presence of polyvictimization in itself may have a considerable effect in terms of psychological impairment among young people.

One line of future research would be to consider other adversities or stressors in a child's life, for example, other forms of interpersonal victimizations not included in this study but which may nonetheless have an effect on psychological wellbeing (e.g., Turner et al., 2006). From a developmental victimology perspective the importance of these findings is that they suggest the need for a more comprehensive approach to the study of child victimization. In line with a point made by Turner et al. (2006, 2010b), these results suggest that those studies which have considered the association between a single type of victimization and the presence of symptoms of psychopathology may have overestimated the strength of this association.

\section{Conclusions}

The present study shows cross-culturally, through a comprehensive measure of victimization and an empirical method, that a well-defined polyvictimized group can be identified within adolescent outpatients. Also, it reveals that polyvictimization is not only associated with symptomatology but also with greater clinical severity. Furthermore, the finding that internalizing symptomatology was associated with polyvictimization when using adolescent self-reports deserves further attention, since this result has not been obtained in other studies with clinical samples (Ford et al., 2009, 2011).

\section{References}

Achenbach, T. M., \& Rescorla, L. A. (2001). Manual for the ASEBA School. Age forms E profiles. Burlington, VT: University of Vermont, Research Center for Children, Youth \& Families.

American Psychiatric Association. (2000). Diagnostic and statistical manual of mental disorders (4th ed., text revision). Washington, DC: Author.

Anda, R., Felitti, V., Bremner, D., Walker, J., Whitfield, C., Perry, B. D., Dube, S. R., \& Giles, W. H. (2006). The enduring effects of abuse and related adverse experiences in childhood. A convergence of evidence from neurobiology and epidemiology. European Archives of Psychiatry and Clinical Neuroscience, 256, 174-186. http://dx.doi.org/10.1007/s00406-005-0624-4

Boxer, P., \& Terranova, A. (2008). Effects of multiple maltreatment experiences among psychiatrically hospitalized youth. Child Abuse E Neglect, $32,637-647$. http://dx.doi.org/10.1016/j.chiabu.2008.02.003

Chartier, M. J., Walker, J. R., \& Naimark, B. (2010). Separate and cumulative effects of adverse childhood experiences in predicting adult health and health care utilization. Child Abuse E Neglect, 34, 454-464. http://dx.doi.org/10.1016/j.chiabu.2009.09.020

Cook, A., Spinazzola, J., Ford, J., Lanktree, C., Blaustein, M., Cloitre, M., DeRosa, R., Hubbard, R., Kagan, R., Liautaud, J., Mallah, K., Olafson, E., \& van der Kolk, B. (2005). Complex trauma in children and adolescents. Psychiatric Annals, 35, 390-398.

Cuevas, C., Finkelhor, D., Clifford, C., Ormrod, R., \& Turner, H. (2010). Psychological distress a risk factor for re-victimization in children. Child Abuse E Neglect, 34, 235-243. http://dx.doi.org/10.1016/j.chiabu.2009.07.004

Cuevas, C., Finkelhor, D., Ormrod, R., \& Turner, H. (2009). Psychiatric diagnosis as a risk marker for victimization in a national sample of children. Journal of Interpersonal Violence, 24, 636-652. http://dx.doi.org/10.1177/0886260508317197

Cyr, K., Chamberland, C., Clément, M. E., Lessard, G., Wemmers, J. A., Collin-Vézina, D., Gagné, M.-H., \& Damant, D. (2013). Polyvictimization and victimization of children and youth: Results from a populational survey. Child Abuse E Neglect, http://dx.doi.org/10.1016/j.chiabu.2013.03.009 (advance online publication)

Fehon, D. C., Grillo, C. M., \& Lipschitz, D. S. (2001). Correlates of community violence exposure in hospitalized adolescents. Comprehensive Psychiatry, 42, 283-290. http://dx.doi.org/10.1053/comp.2001.24580

Finkelhor, D. (2008). Childhood victimization. Violence, crime and abuse in the lives of young people. New York, NY: Oxford University Press. 
Finkelhor, D., Hamby, S., Ormrod, R., \& Turner, H. (2005). The Juvenile Victimization Questionnaire: Reliability, validity, and national norms. Child Abuse E Neglect, 29, 383-412. http://dx.doi.org/10.1016/j.chiabu.2004.11.001

Finkelhor, D., Ormrod, R., \& Turner, H. (2007). Polyvictimization and trauma in a national longitudinal cohort. Development and Psychopathology, 19, 149-166. http://dx.doi.org/10.1017/S0954579407070083

Finkelhor, D., Ormrod, R. K., \& Turner, H. A. (2009). Lifetime assessment of polyvictimization in a national sample of children and youth. Child Abuse $\mathcal{E}$ Neglect, 33, 403-411. http://dx.doi.org/10.1016/j.chiabu.2008.09.012

Finkelhor, D., Ormrod, R., Turner, H., \& Hamby, S. (2005). Measuring poly-victimization using the Juvenile Victimization Questionnaire. Child Abuse E Neglect, 29, 1297-1312. http://dx.doi.org/10.1016/j.chiabu.2005.06.005

Ford, J. D., Connor, D. F., \& Hawke, J. (2009). Complex trauma among psychiatrically impaired children: A cross sectional, chart-review study. Journal of Clinical Psychiatry, 70, 1155-1163. http://dx.doi.org/10.4088/JCP.08m04783

Ford, J., Elhai, J., Connor, D., \& Frueh, C. (2010). Poly-victimization and risk of posttraumatic, depressive, and substance use disorders and involvement in delinquency in a national sample of adolescents. Journal of Adolescent Health, 46, 545-552. http://dx.doi.org/10.1016/j.adohealth.2009.11.212

Ford, J. D., \& Kidd, P. (1998). Early childhood trauma and disorders of extreme stress as predictors of treatment outcome with chronic posttraumatic stress disorder. Journal of Traumatic Stress, 11, 743-761. http://dx.doi.org/10.1023/A:1024497400891

Ford, J. D., Wasser, T., \& Connor, D. F. (2011). Identifying and determining the symptom severity associated with polyvictimization among psychiatrically impaired children in the outpatient setting. Child Maltreatment, 16(3), 216-226. http://dx.doi.org/10.1177/1077559511406109

Guerra, N. G., Williams, K. R., \& Sadek, S. (2011). Understanding bullying and victimization during childhood and adolescence: A mixed methods study. Child Development, 82, 295-310. http://dx.doi.org/10.1111/j. 1467-8624.2010.01556.x

Hamby, S. L., \& Finkelhor, D. (2001). Choosing and using child victimization questionnaires (NCJ186027). Washington, DC: U.S. Department of Justice, Office of Juvenile Delinquency and Prevention.

Higgins, D. (2004). The importance of degree versus type of maltreatment: A cluster analysis id child abuse types. Journal of Psychology, 138, 303-324. http://dx.doi.org/10.3200/JRLP.138.4. 303-324

Higgins, D., \& McCabe, M. (2000). Relationships between different types of maltreatment during childhood and adjustment in adulthood. Child Maltreatment, 5(3), 261-272. http://dx.doi.org/10.1177/1077559500005003006

Hollingshead, A. B. (1975). Four-factor index of social status. New Haven, CT: Yale University (unpublished manuscript).

Ivanova, M. Y., Achenbach, T. M., Rescorla, L. A., Dumenci, L., Almqvist, F., Bilenburg, N., Bird, H., Broberg, A. G., Dobrean, A., Döpfner, M., Erol, N., Forns, M., Hannesdottir, H., Kanbayashi, Y., Lambert, M. C., Leung, P., Minaei, A., Mulatu, M. S., Novik, T., Oh, K. J., Roussos, A., Sawyer, M., Simsek, Z., Steinhausen, H.-C., Weintraub, S., Metzke, C. W., Wolanczyk, T., Zilber, N., Zukauskiene, R., \& Verhulst, F. C. (2007). The generalizability of the Youth Self-Report syndrome structure in 23 countries. Journal of Consulting and Clinical Psychology, 75, 729-738. http://dx.doi.org/10.1037/0022-006X.75.5.729

Jaffe, S. R., Caspi, A., Moffitt, T. E., \& Taylor, A. (2004). Physical maltreatment victim to antisocial child: Evidence of an environmentally mediated process. Journal of Abnormal Psychology, 113, 44-55. http://dx.doi.org/10.1037/0021-843X.113.1.44

Larson, E. (1997). Sleep disturbance, fears, and global adjustment in clinical samples of sexually abused and nonsexually abused children. Dissertation Abstracts International: Section B. The Sciences and Engineering, 57(10b), 6581.

Leventhal, J. M. (2007). Children's experiences of violence: Some have much more than others. Invited Commentary. Child Abuse E Neglect, 31, 3-6. http://dx.doi.org/10.1016/j.chiabu.2006.11.001

Nemeroff, C. B., Heim, C. M., Thase, M. E., Klein, D. N., Rush, A. J., Schatzberg, A. F., Ninan, P. T., McCullough, J. P., Jr., Weiss, P. M., Dunner, D. L., Rothbaum, B. O., Kornstein, S., Keitner, G., \& Keller, M. B. (2003). Differential responses to psychotherapy versus pharmacotherapy in patients with chronic forms of major depression and childhood trauma. Proceedings of the National Academy of Sciences of United States of America, $100,14293-14296$. http://dx.doi.org/10.1073/pnas.2336126100

Pereda, N., Guilera, G., Forns, M., \& Gómez-Benito, J. (2009). The prevalence of child sexual abuse in community and student samples: A meta-analysis. Clinical Psychology Review, 29, 328-338. http://dx.doi.org/10.1016/j.chiabu.2008.07.007

Radford, L., Corral, S., Bradley, C., \& Fisher, H. (2013). The prevalence and impact of child maltreatment and other types of victimization in the UK: Findings from a population survey of caregivers, children and young people and young adults. Child Abuse E Neglect, http://dx.doi.org/10.1016/j.chiabu.2013.02.004 (advance online publication)

Reijntjes, A., Kamphuis, J. H., Prinzie, P., \& Telch, M. J. (2010). Peer victimization and internalizing problems in children: A meta-analysis of longitudinal studies. Child Abuse E Neglect, 34, 244-252. http://dx.doi.org/10.1016/j.chiabu.2009.07.009

Scott, K. M., Smith, D. R., \& Ellis, P. M. (2010). Prospectively ascertained child maltreatment and its association with DMS-IV mental disorders in young adults. Archives of General Psychiatry, 67, 712-719. http://dx.doi.org/10.1001/archgenpsychiatry.2010.71

Turner, H., Finkelhor, D., \& Ormrod, R. (2006). The effect of lifetime victimization on the mental health of children and adolescents. Social Science E Medicine, 62, 13-27. http://dx.doi.org/10.1016/j.socscimed.2005.05.030

Turner, H., Finkelhor, D., \& Ormrod, R. (2010a). Child mental health problems as risk factors for victimization. Child Maltreatment, 15, 132-143. http://dx.doi.org/10.1177/1077559509349450

Turner, H., Finkelhor, D., \& Ormrod, R. (2010b). Poly-victimization in a national sample of children and youth. American Journal of Preventive Medicine, 38 323-330. http://dx.doi.org/10.1016/j.amepre.2009.11.012

Turner, H., Vanderminder, J., Finkelhor, D., Hamby, S., \& Shattuck, A. (2011). Disability and victimization in a national sample of children and youth. Child Maltreatment, 16, 275-286. http://dx.doi.org/10.1177/1077559511427178

Whitaker, D. J., Le, B., Hanson, R. K., Baker, C. K., McMahon, P. M., Ryan, G., Klein, A., \& Rice, D. D. (2008). Risk factors for the perpetration of child sexual abuse: A review and metaanalysis. Child Abuse E Neglect, 32, 529-548. http://dx.doi.org/10.1016/j.chiabu.2007.08.005

Zolotor, A. J., Theodore, A. D., Runyan, D. K., Chang, J. J., \& Laskey, A. L. (2011). Corporal punishment and physical abuse: Population-based trends for three-to-11-year-old children in the United States. Child Abuse Review, 20, 57-66. http://dx.doi.org/10.1002/car.1128

Zubeidat, I., Fernández-Parra, A., Ortega1, J., Vallejo, M. A., \& Sierra, J. C. (2009). Características psicosociales y psicopatológicas en una muestra de adolescentes españoles a partir del Youth Self-Report/11-18. Anales de Psicología, 25(1), 60-69. http://dx.doi.org/10.6018/analesps.25.1.71501

\section{Appendix A. Supplementary data}

Supplementary data associated with this article can be found, in the online version, at http://dx.doi.org/10.1016/ j.chiabu.2013.09.005. 